\title{
Alternative Research (3Rs) in the World, Asia and Japan
}

\author{
Tsutomu Miki Kurosawa( ${ }^{(\varpi)}$ \\ Joint Faculty of Veterinary Medicine, Kagoshima University, Kagoshima, Japan \\ japanawrl@gmail.com
}

\begin{abstract}
Alternative research is currently conducted all over the world and its recent progress is remarkable as $3 \mathrm{Rs}$ research. This article describes a review of alternative research and 3Rs in the world, Asia and Japan.
\end{abstract}

\section{The World}

"Principles of Humane Experimental Technique" were first articulated in the 1950s by Russell and Burch (1959), giving birth to a new field of laboratory animal welfare and the "3Rs" concept of replacement, reduction and refinement in life sciences research. A decade later, the Fund for the Replacement of Animals in Medical Experiments (FRAME 2018) was founded, with a mission to support alternative research, together with the journal Alternatives to Laboratory Animals (ATLA), which has become a leading academic journal of this field.

In 1981, the Center for Alternatives to Animal Testing (CAAT) was founded at Johns Hopkins University. The center co-organized the 1st World Congress on Alternatives and Animal Use in the Life Sciences in 1993 (CAAT 2018). The first president of World Congress of Alternatives was Dr. Alan Goldberg and then he is one of the prominent leaders of this field. His remarkable effort of alternatives to animal testing in toxicology is realistic strategy for alternative research. Because the most of chemicals should be tested their safety before marketing, the toxicological study using animals was a common sense in this field. However, Dr. Goldberg proposes many nonanimal testing methods for their safety.

The European Reference Laboratory for Alternatives to Animal Testing (EURLECVAM) (ECVAM 2018), founded in 1991 as the European Centre for the Validation of Alternative Methods, was given a new name and broader mandate in 2010 for promoting the not only scientific but also regulatory acceptance of non-animal tests which are of importance to biomedical sciences. EURL-ECVAM does so by supporting research, test development and validation, the establishment of a specialised database service, and engagement with international academic organizations in this field. Their targets include chemicals and products of various kinds, including medicines, vaccines, medical devices, cosmetics, household products and agricultural products. 
The US Interagency Coordinating Committee on the Validation of Alternative Methods (ICCVAM) was established by law in 2000 (ICCVAM 2018) as a permanent committee of the NIEHS under the National Toxicology Program Interagency Center for the Evaluation of Alternative Toxicological Methods (NICEATM). ICCVAM is composed of representatives from 16 federal regulatory and research agencies that require, use, generate, or disseminate toxicological and safety testing information. The importance of alternative research is beginning to shift from scientific to regulatory needs.

For animal welfare, the Council for International Organaization of Medical Science (CIOMS) published International Guiding Principles for Biomedical Research Involving Animals in 1985. This principle is proposed by scientific group and the regulatory bodies of animal welfare of many governments was accepted its concepts. These principles were revised in 2012 in conjunction with the International Council for Laboratory Animal Science (CIMOS and ICLAS 2018).

The International Standardisation Organization (ISO) also created an international document "Animal Welfare Requirement" as ISO 10993-2 in 1996 (ISO 2018). This standard is for biological and clinical evaluation of medical devices and then it is revised regularly to expand their target.

The World Animal Health Organization (OIE) is also keen to protect animal health and has introduced animal welfare as a part of animal health. The international standard of animal health (OIE Terrestrial Animal Health Code) includes not only domestic animal welfare but also research animal welfare (OIE 2018).

\section{Asia}

In Asia, the Japanese Society for Alternatives to Animal Experiments (JSAAE) was founded in 1984 as a world-first academic society consisting of scientists for alternative research (Sugawara 1990), and today JSAAE collaborates with many international organizations in this field. JSAAE is a scientific organization that undertakes research, development, education, and surveillance activities for promoting international acceptance of the $3 \mathrm{Rs}$ as guiding principles for the proper use of animals in scientific testing. JSAAE has published its academic journal Alternatives to Animal Testing and Experimentation (AATEX) since 1990, making it one of the oldest academic journals in this field (AATEX 2018). The society celebrated its $30^{\text {th }}$ annual meeting in 2017 (JSAAE 2018).

The $6^{\text {th }}$ World Congress on Alternatives was invited to Tokyo in 2006. The congress included three satellite meetings in other Asian parts, namely Beijing, Seoul and Kyoto, making it a milestone of expansion of alternative research into Asian region. Indeed, the Korean Society for Alternatives to Animal Experiments (KSAAE) was founded that same year.

The Asian Federation of Laboratory Animal Science Associations (AFLAS) is one of other remarkable activities of alternatives research. The first congress was held in Nagasaki in 2004, with subsequent meetings every two years. In 2016 the congress was 
hosted in Singapore (AFLAS 2018), where subjects discussed included laboratory animal welfare and 3 Rs with other subjects in laboratory animal science. The AFLAS membership is now expanded to 11 .

\section{Japan}

In Japan, JSAAE has a central position to propagate 3Rs activities. The initial activities of JASSE were focused on cosmetics. However, since Japan's Animal Welfare Act took $3 \mathrm{Rs}$ as key words, the concept has become well recognized by biomedical research organizations. The practical activities of $3 \mathrm{Rs}$ are held by the Japanese Association of Laboratory Animal Science (JALAS), the Japanese Society of Laboratory Animal and Environment (JSLAE), and the Japanese Association for Experimental Animal Technologists (JAEAT) as education and training sessions. Through these efforts, the 3 Rs are now expanding to be recognized by industries.

Today, the 3Rs are now accepted in Asian countries widely, culminating in the first biennial Asian Congress on Alternatives being organized in 2016 in Karatsu, Japan (Asian Congress 2018). In the future, the World Congress on Alternatives is expected to be held in Asia again as well.

\section{References}

Russell WMS, Burch RL (1959) The principles of humane experimental technique. http://altweb. jhsph.edu/pubs/books/humane_exp/het-toc

FRAME (2018) History - The FRAME story. https://frame.org.uk/researching-alternatives-toanimal-testing/history/

CAAT (2018) CAAT history. http://caat.jhsph.edu/about/history.html

EURL ECVAM (2018) Home. https://eurl-ecvam.jrc.ec.europa.eu/

ICCVAM (2018) About ICCVAM. https://ntp.niehs.nih.gov/pubhealth/evalatm/iccvam/index. html

CIOMS, ICLAS (2018) International guiding principles for biomedical research involving animals. http://iclas.org/wp-content/uploads/2013/03/CIOMS-ICLAS-Principles-Final.pdf

ISO (2018) Biological evaluation of medical devices - Part 2: animal welfare requirement. https://www.iso.org/standard/36405.html

OIE (2018) Use of animals in research and education in terrestrial animal health code. http:// www.oie.int/index.php?id=169\&L=0\&htmfile=chapitre_aw_research_education.htm

Sugawara T (1990) For the first issue of the journal AATEX 1(1):1

AATEX (2018) AATEX (Alternatives to animal testing and experimentation). http://www.asas. or.jp/jsaae/magazine/index.html. ISSN: 1344-0411

JSAAE (2018) The 30th annual meeting of the japanese society for alternatives to animal experiments 2017. http://www.asas.or.jp/jsaae/eng/events/taikai.html

AFLAS (2018) Asian federation of laboratory animal science associations. http://www.aflasoffice.org/aboutus.html

Asian Congress (2018) Asian Congress 2016 on alternatives and animal use in the life science. http://www.asas.or.jp/jsaae/eng/events/asiancongress2016.html 
Open Access This chapter is licensed under the terms of the Creative Commons Attribution 4.0 International License (http://creativecommons.org/licenses/by/4.0/), which permits use, sharing, adaptation, distribution and reproduction in any medium or format, as long as you give appropriate credit to the original author(s) and the source, provide a link to the Creative Commons licence and indicate if changes were made.

The images or other third party material in this chapter are included in the chapter's Creative Commons licence, unless indicated otherwise in a credit line to the material. If material is not included in the chapter's Creative Commons licence and your intended use is not permitted by statutory regulation or exceeds the permitted use, you will need to obtain permission directly from the copyright holder.

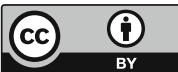

